\title{
A Wireless Transmission System Powered by an Enzyme Biofuel Cell Implanted in an Orange
}

\author{
Kevin MacVittie, ${ }^{\mathrm{a}}$ Tyler Conlon, ${ }^{\mathrm{b}}$ and Evgeny Katz ${ }^{\mathrm{a} *}$ \\ ${ }^{a}$ Department of Chemistry and Biomolecular Science, Clarkson University, Potsdam, NY \\ 13699, USA \\ ${ }^{\mathrm{b}}$ Department of Business, Clarkson University, Potsdam, NY 13699, USA \\ * Corresponding author E-mail address: ekatz@ clarkson.edu; Tel.: 1-315-268-4421; Fax: \\ $1-315-268-6610$
}

\begin{abstract}
A biofuel cell composed of catalytic electrodes made of "buckypaper" modified with PQQ-dependent glucose dehydrogenase and FAD-dependent fructose dehydrogenase on the anode and with laccase on the cathode was used to activate a wireless information transmission system. The cathode/anode pair was implanted in orange pulp extracting power from its content (glucose and fructose in the juice). The open circuit voltage, $\mathrm{V}_{\mathrm{oc}}$, short circuit current density, $\mathrm{j}_{\mathrm{sc}}$, and maximum power produced by the biofuel cell, $\mathrm{P}_{\max }$, were found as ca. $0.6 \mathrm{~V}$, ca. $0.33 \mathrm{~mA} \cdot \mathrm{cm}^{-2}$ and $670 \mu \mathrm{W}$, respectively. The voltage produced by the biofuel cell was amplified with an energy harvesting circuit and applied to a wireless transmitter. The present study continues the research line where different implantable biofuel cells are used for activation of electronic devices. The study emphasizes the biosensor and environmental monitoring applications of implantable biofuel cells harvesting power from natural sources, rather than their biomedical use.
\end{abstract}

Keywords: Implantable biofuel cell, Wireless transmission, Orange, Glucose dehydrogenase, Fructose dehydrogenase, Laccase 


\section{Introduction}

Recent developments in the area of enzyme-based biofuel cells [1-9] resulted in the devices operating in vivo being implanted in various living animals [10,11], including insects [12], mollusks (snail and clams) [13,14], lobsters [15], rats [16-21] and rabbits [22]. From the very beginning [23], this research was directed to micro- [24,25] and even nano-size [26] devices providing power for implantable biomedical/bioelectronic systems [27], e.g., pacemakers [28]. Indeed, some preliminary results for the activation of pacemakers by implantable biofuel cells using enzyme-based biocatalytic electrodes [29] or "abiotic" electrodes based on inorganic catalytic species [30-32] have demonstrated such possibility, while operating in vitro in model systems. However, the first successful demonstrations of the pacemaker operation upon extracting electrical power from glucose in biofluids or model solutions also revealed the limitations of this approach. In order to obtain the required power for the pacemaker operation, the electrodes should have significant size (a few centimeters square), which makes their implantation in a human blood circulation problematic. More importantly, the life-time of the enzyme-based biocatalytic electrodes is incomparable to duration required for the operation of implantable medical devices. Note that a battery used for powering of a pacemaker can normally operate for about 10 years [28], while the life-time of implantable enzymebiofuel cells is in the range of days or at very best months $[1,13]$. The chances that "abiotic" biocatalytic electrodes based on inorganic catalysts [30], can reach the operational time comparable with batteries, particularly operating in biofluids, $[33,34]$ are also illusive, at least at the present level of technology. While in the long perspective the biofuel cells might be improved to meet the requirements for their medical use in implanted devices, in the short run, based on the present level of technology, the biofuel cells should find other potential applications which might be practically important for much shorter time of operation. This could be activation of biosensors for environmental monitoring, homeland security, and even military applications by extracting power from biological sources. The potential power sources might include animals or plants, while the biocatalytic electrodes could be minimally invasive [35] or even located on their surface being printed as a "tattoo" [36]. This application could be practically meaningful 
for the operational time comparable with the stability of the biocatalytic electrodes achievable already at the present level of technology. The first examples of the biofuel cells extracting power from the abundant "fuel" in plants were already reported using enzyme-modified electrodes implanted in a grape [37] or simply immersed in fruit juice $[22,38]$. On the other hand, some other experiments on non-implantable biofuel cells have demonstrated activation of electronic sensing systems for wireless information transmission $[39,40]$.

It should be noted that the biofuel cells utilizing abundant biofuels (e.g., glucose or fructose) and oxygen as the electron acceptor have the open circuit voltage thermodynamically limited by the potential difference between the oxidation potential of the biofuel and reduction potential of oxygen. Upon extracting current from the biofuel cell this voltage is further decreased and limited by the kinetics of the redox processes, including the mass transport, interfacial electron transfer, and ohmic resistance [9]. Overall, the operational voltage of biofuel cells is usually in the range of several hundred millivolts [1,9] and it is rarely overshot half a volt [41-43]. On the other side, the operational voltage of most of electronic devices, including medical implantable micropower systems [44], is in the range of several volts [45]. This voltage mismatch should be managed with electronics, which can increase the DC-voltage produced by the biofuel cell to meet the requirements of the power-consuming electronic systems [39,40]. Usually this is achieved with the use of charge pumps increasing DC-voltage at the expense of consuming more current [46]. This puts additional requirements on the current produced by the implantable biofuel cells, thus resulting in larger electrodes, unless the current density is increased upon using more efficient electrocatalysts. Overall, the question to be experimentally answered is whether the biocatalytic electrodes implanted in any source of biofuel are capable of extracting enough current to power the DCvoltage converter as well as the wireless transmitter, as an example for practically meaningful applications. The current produced by micro- [24,25] and nano-size [26] implantable biocatalytic electrodes, particularly implanted in insects, mollusks, grapes and other small biological species is too small to be practically useful [47], at least at the present level of the electrode electrocatalytic efficiency. Thus, we experimented with 
oranges which can provide easily available juicy fuel combined with a reasonable size for implanting electrodes of substantially large size.

The present paper reports on the first preliminary results which show the power production by enzyme biofuel cell operating in vivo in an orange and used for activation of wireless electronics.

\section{Experimental}

\subsection{Chemicals and materials}

PQQ-dependent glucose dehydrogenase (GDH; E.C. 1.1.5.2, from microorganism - not specified by the company) was purchased from Toyobo Co., Japan, and used as supplied. Laccase (E.C.1.10.3.2, from Trametes versicolor) was obtained from SigmaAldrich and used in experiments after the purification procedure described elsewhere [48]. 1-pyrenebutanoic acid succinimidyl ester (PBSE) was purchased from AnaSpec Inc. FAD-dependent D-fructose dehydrogenase (FDH; E. C. 1.1.99.11, from Gluconobacter industrius $), \quad \mathrm{D}-(+)$-glucose $\quad(\geq 99.5 \%), \quad \mathrm{D}-(-)$-fructose $\quad(\geq 99 \quad \%), \quad 3-(N-$ morpholino)propanesulfonic acid (MOPS-buffer) and other standard chemicals were purchased from Sigma-Aldrich and used as supplied without any further purification. Water used in all of the experiments was ultrapure $(18.2 \mathrm{M} \Omega \cdot \mathrm{cm})$ from a NANOpure Diamond (Barnstead) source. Washington Navel Oranges (http://www.citrusvariety.ucr.edu/citrus/washington.html) were purchased from Walmart Supermarket (containing 1.98-2.05 g/100 mL fructose and 1.82-1.83 g/100 mL glucose in the juice) [49]. The average orange size was $8 \pm 1.5 \mathrm{~cm}$ diameter.

\subsection{Electrode preparation}

Buckypaper composed of compressed multi-walled carbon nanotubes (Buckeye Composites; NanoTechLabs, Yadkinville, NC) was used as the electrode material. Electrodes were washed with isopropyl alcohol with moderate shaking for $15 \mathrm{~min}$ at 
room temperature prior to their modification. The electrodes were incubated with PBSE, $10 \mathrm{mM}$, in ethanol with moderate shaking for $1 \mathrm{~h}$ at room temperature, subsequently rinsed with ethanol to remove excess of PBSE and then with MOPS-buffer $(50 \mathrm{mM}, \mathrm{pH}$ 7.0) to remove ethanol. The biocatalytic anodes were prepared by immobilization of GDH and FDH. The PBSE-functionalized electrode was incubated for 1 hour in the solution of GDH $\left(2.4 \mathrm{mg} \cdot \mathrm{mL}^{-1}\right)$ and FDH $\left(0.5 \mathrm{mg} \cdot \mathrm{mL}^{-1}\right)$ in MOPS-buffer $(50 \mathrm{mM}$, pH 7.0) containing $\mathrm{Na}_{2} \mathrm{SO}_{4}(100 \mathrm{mM})$ and $1 \mathrm{mM} \mathrm{CaCl}_{2}(1 \mathrm{mM})$. The biocatalytic cathode was prepared by immobilization of laccase. The PBSE-functionalized electrode was incubated for 1 hour in the solution of laccase $\left(1.5 \mathrm{mg} \cdot \mathrm{mL}^{-1}\right)$ in potassium phosphate buffer $(10 \mathrm{mM}, \mathrm{pH} 7.0)$. The immobilization reactions proceeded at room temperature with moderate shaking. Then the enzyme-modified electrodes were stored $\left(4^{\circ} \mathrm{C}\right)$ in the same buffer until implanted in oranges.

\subsection{Electrochemical characterization of the modified electrodes}

Cyclic voltammetry measurements were carried out using a conventional threeelectrode cell at room temperature $\left(22 \pm 2{ }^{\circ} \mathrm{C}\right)$ with an ECO Chemie Autolab PASTAT 10 electrochemical analyzer using the GPES 4.9 (General Purpose Electrochemical System) software package. The working electrode was made of buckypaper and modified with the enzymes as described above. The geometrical surface area exposed to the solution was $2 \mathrm{~cm}^{2}$, accounting for both sides of the modified electrodes, but not taking into account the internal surface of the 3D-electrodes. A slab of glassy carbon $\left(6.48 \mathrm{~cm}^{2}\right.$ geometrical surface area) was used as a counter electrode and a Metrohm $\mathrm{Ag}|\mathrm{AgCl}| \mathrm{KCl}, 3$ M, electrode served as a reference electrode. Cyclic voltammograms were recorded at a scan rate of $2 \mathrm{mV} \cdot \mathrm{s}^{-1}$ in a phosphate buffered $(0.2 \mathrm{M}, \mathrm{pH} 7.4)$ electrolyte solution. For experiments without oxygen, the solution was deoxygenated by bubbling argon prior to the cyclic voltammetry measurements. The cathodic electrocatalytic reduction of oxygen was studied in the solution containing soluble oxygen, being in equilibrium with air (ca. $0.25 \mathrm{mM} \mathrm{O}_{2}$ under these experimental conditions) [50]. The anodic electrocatalytic oxidation of biomolecular "fuels" was studied in the solutions containing $20 \mathrm{mM}$ glucose or $20 \mathrm{mM}$ fructose. 


\subsection{Biofuel cell polarization curve measurements}

The performance of the biofuel cell was analyzed with the biocatalytic electrodes implanted in orange. The peel was cut and partially removed together with a small segment inside, providing the necessary space for the electrodes. Then the catalytic anode-cathode pair (each electrode with the geometrical surface area of ca. $7.5 \mathrm{~cm}^{2}$ accounting for both electrode sides) was inserted into the pulp with the distance between the electrodes of ca. $1 \mathrm{~cm}$, Scheme 1, inset. Note that the cut resulted in destroying the juice vesicles and the electrodes were allowed to contact their juicy content. A polarization function was obtained when the cell was connected to an external variable resistance load (varied from 0 to $900 \mathrm{k} \Omega$ ) and the voltage/current produced on the load was measured by a high impedance multimeter (Meterman 37XR). The polarization measurements were performed ex situ in the orange explanted from a tree. The experiments were repeated with 5 oranges from the same batch.

\subsection{The energy harvesting circuit design and wireless transmitting system}

A charge pump was used to amplify the low voltage produced by the biofuel cell to $2.3 \mathrm{~V}$, a level required by the wireless transmitting system. The used charge pump included two main components. A commercially available EH4295 unit (Advanced Linear Devices, Inc., CA) first harvested the low voltage electrical power from the biofuel cell; then the electrical power was sent to the EH300 companion unit. The latter was applied to charge the onboard $1 \mathrm{mF}$ capacitor. This onboard capacitor was configured in parallel with an external $6.8 \mathrm{mF}$ super-capacitor. The final super-capacitor was chosen for its high storage capacity, small size, and low current leakage. This was then connected to the wireless transmission device. The radio transmission module consists of 2 main components: a UHF OOK radio transmitter combined with an ATTiny 85 micro-controller. The radio transmitter sent data at 9600 baud. The data sent by this transmitter was read by a companion receiver circuit connected to a standard desktop PC. Reception of the transmitted data is provided by an integrated radio receiver module 
coupled with a Cortex M4 micro controller. This receiver module is paired with the transmitter by the manufacturer. The micro-controller's role is to filter the raw received data so only data from our transmitter is displayed on the computer.

\subsection{The in situ experiment with the orange growing on a tree.}

A Washington Navel Orange tree (http://backyardfruit.com/navel-orangetree.htm) was used for the in situ experiments. The average orange size was ca. $5 \mathrm{~cm}^{2}$ diameter, and the glucose and fructose concentrations were 1.82-1.83 and 1.98-2.05 $\mathrm{g} / 100 \mathrm{~mL}$, respectively [49]. The biocatalytic electrodes were implanted in the orange located on the tree and the $\mathrm{V}_{\mathrm{oc}}$ value was measured in situ, followed by the wireless transfer experiment.

\section{Results and Dicussion}

Scheme 1 shows the block-schematics of the experimental setup, which includes an orange with implanted electrodes, power/voltage managing electronic system and wireless transmitting/receiving electronics.

The biocatalytic electrodes were prepared using a 3D-conducting matrix made of compressed multi-walled carbon nanotubes (CNTs) called "buckypaper". This material was already successfully used for preparing enzyme-modified biocatalytic electrodes in biosensors and biofuel cells providing direct (non-mediated) electron transfer between enzyme active centers and the conducting support [43,51]. Particularly, this material provided direct electrical contact with PQQ-dependent glucose dehydrogenase [13-15,52] and laccase [48,53], both important for use in biofuel cells. Fructose dehydrogenase was also immobilized on some other nano-structured electrodes demonstrating direct electron transfer from the enzyme active centers [54,55]. The importance of nano-structured electrodes for non-mediated direct electron transfer with enzymes, particularly when they are used in implanted biofuel cells, was discussed in details elsewhere [47,56]. While laccase is the most frequently used enzyme for the cathodic reduction of oxygen in 
biofuel cells, the anodic glucose oxidation can be achieved through various biocatalytic enzymes (most frequently using glucose oxidase) [1]. Selection of PQQ-dependent glucose dehydrogenase for glucose oxidation in implanted biofuel cells is justified by its operation without electron transfer mediators and with no need of $\mathrm{NAD}^{+}$soluble cofactor [47]. FAD-dependent fructose dehydrogenase is also an oxygen-independent enzyme [57]. Overall, PQQ- and FAD-dependent dehydrogenases are particularly good for their use in biofuel cells due to their oxygen independence, especially in the case of implantable biofuel cells operating in vivo where the anodic space for the biofuel oxidation cannot be separated from the oxygenated cathodic solution. Specifically in the present study, PQQ-dependent glucose dehydrogenase (GDH) and FAD-dependent fructose dehydrogenase (FDH) were used for catalyzing the anodic process because of the high content of glucose and fructose in the orange juice.

Figure 1A shows cyclic voltammograms of the laccase-modified buckypaper electrode obtained in an aqueous buffer solution in the absence and presence of oxygen. The cathodic wave starting at ca. $0.5 \mathrm{~V}$ (vs. $\mathrm{Ag} / \mathrm{AgCl}$ reference electrode) demonstrates the bioelectrocatalytic $\mathrm{O}_{2}$ reduction, Figure $1 \mathrm{~A}$, curve $\mathrm{b}$. Figure 1B demonstrates the anodic oxidation of glucose and fructose by the buckypaper electrode modified with GDH and FDH. Both biocatalytic anodic processes start from ca. $-0.1 \mathrm{~V}$. This potential is close to the redox potential of PQQ [58], which is the active center in GDH, and to the potential of heme c operating as a prosthetic group of FDH [59]. The starting potentials of the bioelectrocatalyzed oxygen reduction and glucose/fructose oxidation allow expectation of the open circuit voltage, $\mathrm{V}_{\mathrm{oc}}$, around $600 \mathrm{mV}$ when the biocatalytic anode and cathode are coupled. Indeed, the polarization function of the GDH/FDH-modified anode and laccase-modified cathode implanted in an orange demonstrates the $\mathrm{V}_{\text {oc }} \mathrm{ca} .600$ $\mathrm{mV}$, Figure 2A. Short circuit current, $\mathrm{I}_{\mathrm{sc}}$, was ca. $2.5 \mathrm{~mA}$ (note current density of ca. 0.33 $\mathrm{mA} \cdot \mathrm{cm}^{-2}$, calculated vs. geometrical electrode surface area), which is consistent with the previously reported $\mathrm{I}_{\mathrm{sc}}$ value obtained for the similar modified electrodes operating in vitro [29], but much higher than all $\mathrm{I}_{\mathrm{sc}}$ values reported for implanted electrodes operating in vivo [47]. The reason for that is rather trivial - the size of oranges used for implantation of electrodes allowed the biocatalytic electrodes of rather big size, $3.75 \mathrm{~cm}^{2}$ 
(7.5 $\mathrm{cm}^{2}$ accounting for both electrode sides). The maximum power extracted from the implanted biofuel cell on the optimum resistance load $(200 \Omega)$ was $670 \mu \mathrm{W}\left(90 \mu \mathrm{W} \cdot \mathrm{cm}^{-}\right.$ ${ }^{2}$ ), Figure 2B. While the achieved power density is not very impressive comparing with the record values [9] obtained for glucose $/ \mathrm{O}_{2}\left(1300 \mu \mathrm{W} \cdot \mathrm{cm}^{-2}\right.$ [43]) and fructose $/ \mathrm{O}_{2}(840$ $\left.\mu \mathrm{W} \cdot \mathrm{cm}^{-2}[60]\right)$ biofuel cells, it should be noted that for practical applications the critical parameter is the total released power rather than calculated power density. When the experiments were repeated with different orange specimens, the deviation of the measured biofuel cell parameters was in the range of $\pm 10 \%$, which is expectable for biological samples. The average values are given in the paper.

The generated power was used for activating an electronic wireless transmitting device, Figure 3A, and the mismatched voltage was corrected with the help of an electronic power harvesting circuit (a charge pump) composed of commercially available EH4295 and EH300 units connected to the onboard $1 \mathrm{mF}$ capacitor and an external 6.8 $\mathrm{mF}$ super-capacitor. The power harvesting system was finally connected to the wireless transmitting device. Wireless transmission was performed using two different methods. For the automatic transmission of the preprogrammed data, the biofuel cell was slowly charging the super-capacitor, Figure 3B. Around 1.5 V obtained on the super-capacitor, the micro-controller turned on, but remained in a sleep-mode only drawing about $7 \mu \mathrm{A}$. Every 32 seconds the micro-controller woke from the sleep-mode and sampled the input voltage. If the input voltage is above the desired threshold (experimentally determined to be optimally ca. $2.3 \mathrm{~V}$ ) the micro-controller powered up the transmitter. The microcontroller then sent a message via TTL serial to the transmitter to be transmitted. Messages were sent inside a packet, so they can be received with little interference. The system continued transmitting until it discharged the super-capacitor to below the $1.5 \mathrm{~V}$ voltage limit necessary for the micro-controller to turn on, which then returns to the sleep mode. After returning to the sleep mode the power conditioning apparatus is able to then recharge the capacitor to the $2.3 \mathrm{~V}$ necessary for the operation to repeat itself (repeating the transmissions every 2 hours), Figure 3B. Additionally wireless transmission was accomplished manually by separating the capacitor from the wireless transmission apparatus using a common single throw single pole switch. In this procedure, the charge 
on the capacitor was monitored and the switch was thrown when the charge had reached the necessary $2.3 \mathrm{~V}$. This resulted in the immediate transmission of data by the UHF OOK radio transmitter operating under the control of the ATTiny 85 micro-controller, Figure 3C. This continued until the device had completely drained the capacitor. The switch was then returned to the disconnected position, allowing the power harvester to recharge the capacitor to ca. $2.3 \mathrm{~V}$ wherein the process was repeated. The manual transmission method was attempted to present a situation where transmission could occur at a faster rate (ca. every 30 minutes), Figure 3C. The automatic transmission setup requires the micro-controller to sample the voltage of the capacitor every 32 seconds. This necessitates the micro-controller be on, even while in the sleep mode, drawing a constant current of $7 \mu \mathrm{A}$. Due to this slow draw of power, the charging of the capacitor under the automatic transmission conditions takes considerably longer time (ca. 8 times as long). The transmitted example message "Clarkson University" was read on a computer equipped with the receiver, Figure 3D. The signal could be read from approximately 10 meters away.

After completing the experiments performed ex situ using the orange separated from a tree and located on a laboratory bench, we performed a short experiment in situ when the orange was growing on a tree, Figure 4 . The $\mathrm{V}_{\mathrm{oc}}$ was measured very similar to the value obtained ex situ. Then connecting the implanted biofuel cell we activated the wireless transmitting device operating in the same way as described above. Obviously, the in situ experiment was very similar to the result obtained ex situ. The only condition which has to be met is the glucose and fructose concentrations, which can vary from tree to tree and from season to season. Also the size of the orange should be large enough to accommodate the electrodes with the dimensions used in the ex situ experiments in order to obtain comparable power.

\section{Conclusions}

The performed experiments demonstrated the possibility of a wireless electronic system activated by the power harvested from an orange. Despite the fact that the 
experimental conditions were much simpler than those when biocatalytic electrodes were surgically implanted in vertebrate animals, such as rats or rabbits [19,22], the obtained results are important for future applications. These applications might be more related to powering biosensors for environmental monitoring, rather than activation of medical implants. The present preliminary results obtained on the biofuel cell which was not properly engineered (the biofuel cell was not designed as a device) are still not enough for immediate use in the field, even though the power was harvested from a tree. The produced power was hardly enough for activation of the wireless transmitting device with the preprogrammed message. In real future applications the higher power will be required to activate a sensor/biosensor and to transfer meaningful information over a long distance (note that the present wireless transmission was only over 10 meters). The operational life-time of the biofuel cell was at least 6 hours without observing power decay (the experiments were not continued longer). However, the long-time activity of similar electrodes implanted in a snail [13] keep promise of much longer operation of the orangebiofuel cell. Increasing the operational time of the biofuel cell will be important for its practical use, however in the aimed biosensing rather than medical application, the lifetime does not have to be in the range of years. All these goals are challenging, but still possible to achieve at the present level of technology. This is the major message from the present study.

\section{Acknowledgment}

Funding of our research by the NSF, via award CBET-1066397, is gratefully acknowledged. 


\section{References}

[1] F. Davis, S.P.J. Higson, Biofuel cells - Recent advances and applications, Biosens. Bioelectron. 22 (2007) 1224-1235.

[2] J. A. Cracknell, K.A. Vincent, F.A. Armstrong, Enzymes as working or inspirational electrocatalysts for fuel cells and electrolysis, Chem. Rev. 108 (2008) 2439-2461.

[3] M.J. Moehlenbrock, S.D. Minteer, Extended lifetime biofuel cells, Chem. Soc. Rev. 37 (2008) 1188-1196.

[4] R.A. Rincón, C. Lau, H.R. Luckarift, K.E. Garcia, E. Adkins, G.R. Johnson, P. Atanassov, Enzymatic fuel cells: Integrating flow-through anode and airbreathing cathode into a membrane-less biofuel cell design, Biosens. Bioelectron. 27 (2011) 132-136.

[5] M. Zhou, S. Dong, Bioelectrochemical interface engineering: Toward the fabrication of electrochemical biosensors, biofuel cells, and self-powered logic biosensors, Acc. Chem. Res. 44 (2011) 1232-1243.

[6] M. Zhou, J. Wang, Biofuel cells for self-powered electrochemical biosensing and logic biosensing: A review, Electroanalysis 24 (2012) 197-209.

[7] D. Leech, P. Kavanagh, W. Schuhmann, Enzymatic fuel cells: Recent progress, Electrochim. Acta 84 (2012) 223-234.

[8] M.T. Meredith, S.D. Minteer, Biofuel cells: Enhanced enzymatic bioelectrocatalysis, Ann. Rev. Anal. Chem. 5 (2013) 157-179.

[9] R.A.S. Luz, A.R. Pereira, J.C.P. de Souza, F.C.P.F. Sales, F.N. Crespilho, Enzyme biofuel cells: Thermodynamics, kinetics and challenges in applicability, ChemElectroChem in press (2014) DOI number: 10.1002/celc.201402141.

[10] U. Schröder, From in vitro to in vivo-Biofuel cells are maturing, Angew. Chem. Int. Ed. 51 (2012) 7370-7372.

[11] M. Falk, C.W. Narváez Villarrubia, S. Babanova, P. Atanassov, S. Shleev, Biofuel cells for biomedical applications: Colonizing the animal kingdom, ChemPhysChem 14 (2013) 2045-2058. 
[12] M. Rasmussen, R.E. Ritzmann, I. Lee, A.J. Pollack, D. Scherson, An implantable biofuel cell for a live insect, J. Am. Chem. Soc. 134 (2012) 1458-1460.

[13] L. Halámková, J. Halámek, V. Bocharova, A. Szczupak, L. Alfonta, E. Katz, Implanted biofuel cell operating in a living snail, J. Am. Chem. Soc. 134 (2012) 5040-5043.

[14] A. Szczupak, J. Halámek, L. Halámková, V. Bocharova, L. Alfonta, E. Katz, Living battery - biofuel cells operating in vivo in clams, Energy Environ. Sci. 5 (2012) 8891-8895.

[15] K. MacVittie, J. Halámek, L. Halámková, M. Southcott, W.D. Jemison, R. Lobel, E. Katz, From "cyborg" lobsters to a pacemaker powered by implantable biofuel cells, Energy Environ. Sci. 6 (2013) 81-86.

[16] P. Cinquin, C. Gondran, F. Giroud, S. Mazabrard, A. Pellissier, F. Boucher, J.-P. Alcaraz, K. Gorgy, F. Lenouvel, S. Mathé, P. Porcu, S. Cosnier, A glucose biofuel cell implanted in rats, PLoS ONE 5 (2010) article \# e10476.

[17] H. Cheng, P. Yu, X. Lu, Y. Lin, T. Ohsaka, L. Mao, Biofuel cell-based selfpowered biogenerators for online continuous monitoring of neurochemicals in rat brain, Analyst 138 (2013) 179-185.

[18] F.C. Sales, R.M. Iost, M.V.A. Martins, M.C. Almeida, F.N. Crespilho, An intravenous implantable glucose/dioxygen biofuel cell with modified flexible carbon fiber electrodes, Lab Chip 13 (2013) 468-474.

[19] A. Zebda, S. Cosnier, J.-P. Alcaraz, M. Holzinger, A. Le Goff, C. Gondran, F. Boucher, F. Giroud, K. Gorgy, H. Lamraoui, P. Cinquin, Single glucose biofuel cells implanted in rats power electronic devices, Sci. Reports 3 (2013) article \# 1516.

[20] J.A. Castorena-Gonzalez, C. Foote, K. MacVittie, J. Halámek, L. Halámková, L.A. Martinez-Lemus, E. Katz, Biofuel cell operating in vivo in rat, Electroanalysis 25 (2013) 1579-1584.

[21] V. Andoralov, M. Falk, D.B. Suyatin, M. Granmo, J. Sotres, R. Ludwig, V.O. Popov, J. Schouenborg, Z. Blum, S. Shleev, Biofuel cell based on microscale nanostructured electrodes with inductive coupling to rat brain neurons, Sci. Reports 3 (2013) article \#3270. 
[22] T. Miyake, K. Haneda, N. Nagai, Y. Yatagawa, H. Onami, S. Yoshino, T. Abe, M. Nishizawa, Enzymatic biofuel cells designed for direct power generation from biofluids in living organisms, Energy Environ. Sci. 4 (2011) 5008-5012.

[23] R.F. Drake, B.K. Kusserow, S. Messinger, S. Matsuda, A tissue implantable fuel cell power supply, Trans. - Am. Soc. Artif. Intern.Organs 16 (1970) 199-205.

[24] S.C. Barton, J. Gallaway, P. Atanassov, Enzymatic biofuel cells for implantable and microscale devices, Chem. Rev. 104 (2004) 4867-4886

[25] A. Heller, Miniature biofuel cells, Phys. Chem. Chem. Phys. 6 (2004) 209-216.

[26] B.J. Hansen, Y. Liu, R. Yang, Z.L. Wang, Hybrid nanogenerator for concurrently harvesting biomechanical and biochemical energy, ACS Nano 4 (2010) 36473652.

[27] E. Katz, (Ed.), Implantable Bioelectronics - Devices, Materials and Applications, Wiley-VCH, Weinheim, Germany, 2014.

[28] K.A. Ellenbogen, G.N. Kay, C.-P. Lau, B.L. Wilkoff, Clinical Cardiac Pacing, Defibrillation, and Resynchronization Therapy, $4^{\text {th }}$ edition, Elsevier, Philadelphia, PA, 2011.

[29] M. Southcott, K. MacVittie, J. Halámek, L. Halámková, W.D. Jemison, R. Lobel, E. Katz, Pacemaker powered by implantable biofuel cell operating under conditions mimicking human blood circulation system - Battery not included, Phys. Chem. Chem. Phys. 15 (2013) 6278-6283.

[30] S. Kerzenmacher, J. Ducrée, R. Zengerle, F. von Stetten, Energy harvesting by implantable abiotically catalyzed glucose fuel cells, J. Power Sources 182 (2008) $1-17$.

[31] S. Kerzenmacher, S. Zehnle, T. Volk, D. Jansen, F. von Stetten, R. Zengerle, An efficient low-power DC-DC converter enables operation of a cardiac pacemaker by an integrated glucose fuel cell, Proc. PowerMEMS 2008+ microEMS2008, Sendai, Japan, November 9-12, pp. 189-192, 2008.

[32] S. Kerzenmacher, S. Rubenwolf, A. Kloke, R. Zengerle, J. Gescher, Biofuel cells for the energy supply of distributed systems: State-of-the-art and applications, Conf. Proc. Sensoren und Messsysteme, Nürnberg, article \#100, pp. 562-565, 2010. 
[33] T. Sharma, Y. Hu, M. Stoller, M. Feldman, R.S. Ruoff, M. Ferrari, X. Zhang, Mesoporous silica as a membrane for ultra-thin implantable direct glucose fuel cells, Lab Chip 11 (2011) 2460-2465.

[34] C. Köhler, M. Frei, R. Zengerle, S. Kerzenmacher, Performance loss of a Pt-based implantable glucose fuel cell in simulated tissue and cerebrospinal fluids, ChemElectroChem in press (2014) DOI: 10.1002/celc.201402138.

[35] W. Jia, G. Valdes-Ramirez, A.J. Bandodkar, J.R. Windmiller, J. Wang, Epidermal biofuel cells: Energy harvesting from human perspiration, Angew. Chem. Int. Ed. 52 (2013) 7233-7236.

[36] W. Jia, A.J. Bandodkar, G. Valdés-Ramírez, J.R. Windmiller, Z. Yang, J. Ramírez, G. Chan, J. Wang, Electrochemical tattoo biosensors for real-time noninvasive lactate monitoring in human perspiration, Anal. Chem. 85 (2013) 6553-6560.

[37] N. Mano, F. Mao, A. Heller, Characteristics of a miniature compartment-less glucose- $\mathrm{O}_{2}$ biofuel cell and its operation in a living plant, J. Am. Chem. Soc. 125 (2003) 6588-6594.

[38] Y. Liu, S. Dong, A biofuel cell harvesting energy from glucose-air and fruit juiceair, Biosens. Bioelectron. 23 (2007) 593-597.

[39] T. Hanashi, T. Yamazaki, W. Tsugawa, K. Ikebukuro, K. Sode, BioRadioTransmitter: A self-powered wireless glucose-sensing system, J. Diabetes Sci. Technol. 5 (2011) 1030-1035.

[40] A. Meehan, H. Gao, Z. Lewandowski, Energy harvesting with microbial fuel cell and power management system, IEEE Trans. Power Electronics 26 (2011) 176181.

[41] N. Mano, F. Mao, A. Heller, A miniature membrane-less biofuel cell operating at +0.60 V under physiological conditions, ChemBioChem 5 (2004) 1703-1705.

[42] V. Soukharev, N. Mano, A. Heller, A four-electron $\mathrm{O}_{2}$-electroreduction biocatalyst superior to platinum and a biofuel cell operating at $0.88 \mathrm{~V}$, J. Am. Chem. Soc. 126 (2004) 8368-8369. 
[43] A. Zebda, C. Gondran, A. Le Goff, M. Holzinger, P. Cinquin, S. Cosnier, Mediatorless high-power glucose biofuel cells based on compressed carbon nanotube-enzyme electrodes, Nature Commun. 2 (2011) article \#370.

[44] Y.-H. Joung, Development of implantable medical devices: From an engineering perspective, Int. Neurourol. J. 17 (2013) 98-106.

[45] B. Razavi, Fundamentals of Microelectronics, Wiley, 2013.

[46] F. Pan, T. Samaddar, Charge Pump Circuit Design, McGraw-Hill Professional, New York, 2006.

[47] E. Katz, K. MacVittie, Implanted biofuel cells operating in vivo - methods, applications and perspectives - feature article, Energy Environ. Sci. 6 (2013) 2791-2803.

[48] G. Strack, H.R. Luckarift, R. Nichols, K. Cozart, E. Katz, G.R. Johnson, Bioelectrocatalytic generation of directly readable code: harnessing cathodic current for long-term information relay, Chem. Commun. 47 (2011) 7662-7664.

[49] E. Çandır, M. Kamiloğlu, D. Üstün, G.T. Kendir, Comparison postharvest quality of conventionally and organically grown 'Washington Navel' oranges, J. Appl. Botany Food Quality 86 (2013) 59-65.

[50] R.F. Weiner, R.A. Mattews, Introduction to Environmental Engineering, $4^{\text {th }}$ ed., Elsevier Science, 2003.

[51] M. Holzinger, A. Le Goff, S. Cosnier, Carbon nanotube/enzyme biofuel cells, Electrochim. Acta 82 (2012) 179-190.

[52] G. Strack, S. Babanova, K.E. Farrington, H.R. Luckarift, P. Atanassov, G.R. Johnson, Enzyme-modified buckypaper for bioelectrocatalysis, J. Electrochem. Soc. 160 (2013) G3178-G3182.

[53] L. Hussein, S. Rubenwolf, F. von Stetten, G. Urban, R. Zengerle, M. Krueger, S. Kerzenmacher, A highly efficient buckypaper-based electrode material for mediatorless laccase-catalyzed dioxygen reduction, Biosens. Bioelectron. 26 (2011) 4133-4138.

[54] S. Kawai, T. Yakushi, K. Matsushita, Y. Kitazumi, O. Shirai, K. Kano, The electron transfer pathway in direct electrochemical communication of fructose dehydrogenase with electrodes, Electrochem. Commun. 38 (2014) 28-31. 
[55] K. So, S. Kawai, Y. Hamano, Y. Kitazumi, O. Shirai, M. Hibi, J. Ogawa, K. Kano, Improvement of a direct electron transfer-type fructose/dioxygen biofuel cell with a substrate-modified biocathode, Phys. Chem. Chem. Phys. 16 (2014) 4823-4829.

[56] A. de Poulpiquet, A. Ciaccafava, E. Lojou, New trends in enzyme immobilization at nanostructured interfaces for efficient electrocatalysis in biofuel cells, Electrochim. Acta 126 (2014) 104-114.

[57] O. Adachi, Y. Ano, H. Toyama, K. Matsushita, In: Modern Biooxidation. Enzymes, Reactions and Applications, R.D. Schmid, V.B. Urlacher, (Eds.), Wiley-VCH, Weinheim, 2007.

[58] E. Katz, D.D. Schlereth, H.-L. Schmidt, Electrochemical study of pyrroloquinoline quinone covalently immobilized as monolayer onto a cystamine modified gold electrode, J. Electroanal. Chem. 367 (1994) 59-70.

[59] M. Tominaga, S. Nomura, I. Taniguchi, D-Fructose detection based on the direct heterogeneous electron transfer reaction of fructose dehydrogenase adsorbed onto multi-walled carbon nanotubes synthesized on platinum electrode, Biosens. Bioelectron. 24 (2009) 1184-1188.

[60] Y. Kamitaka, S. Tsujimura, N. Setoyama, T. Kajino, K. Kano, Fructose/dioxygen biofuel cell based on direct electron transfer-type bioelectrocatalysis, Phys. Chem. Chem. Phys. 9 (2007) 1793-1801. 


\section{Figure Captions:}

Scheme 1. General schematic of the components used for the wireless transmission of information powered by the biofuel cell implanted in an orange. The inset shows the orange with implanted electrodes.

Figure 1. (A) Cyclic voltammograms obtained for the laccase-modified buckypaper electrode in the absence (a) and presence (b) of oxygen. (B) Cyclic voltammograms obtained for the GDH/FDH-modified buckypaper electrode in the absence of glucose/fructose (a), in the presence of $20 \mathrm{mM}$ glucose (b) and in the presence of $20 \mathrm{mM}$ fructose (c). Note that the glucose and fructose biocatalytic oxidation was performed in the presence of $\mathrm{O}_{2}$ in the solution. The background electrolyte was $0.2 \mathrm{M}$ phosphate buffer, $\mathrm{pH} 7.4$, and the potential scan rate was $2 \mathrm{mV} \cdot \mathrm{s}^{-1}$. The schemes show the biocatalyzed reactions on the cathode and anode of the biofuel cell.

Figure 2. (A) Polarization voltage-current dependence of the enzyme biofuel cell operating in an excised and opened orange. (B) The power produced by the implanted biofuel cell as the function of the variable ohmic resistance load.

Figure 3. (A) Electronic circuit containing the ATTiny 85 micro-controller and 434 $\mathrm{MHz}$ OOK wireless transmitter used for the wireless transmission of information (general view). (B) and (C) Voltage variations of the external super-capacitor in the automatic and manual transmission modes, respectively. The asterisks show the time when the voltage reached the value required for activation of the transmitting device and the actual transmission was performed. (D) The wireless transmitted message "Clarkson University" read on a computer screen through the receiver operation. 
Figure 4. The orange tree with an orange containing the implanted biocatalytic electrodes. The inset shows the close view of the electrodes implanted in the orange. 


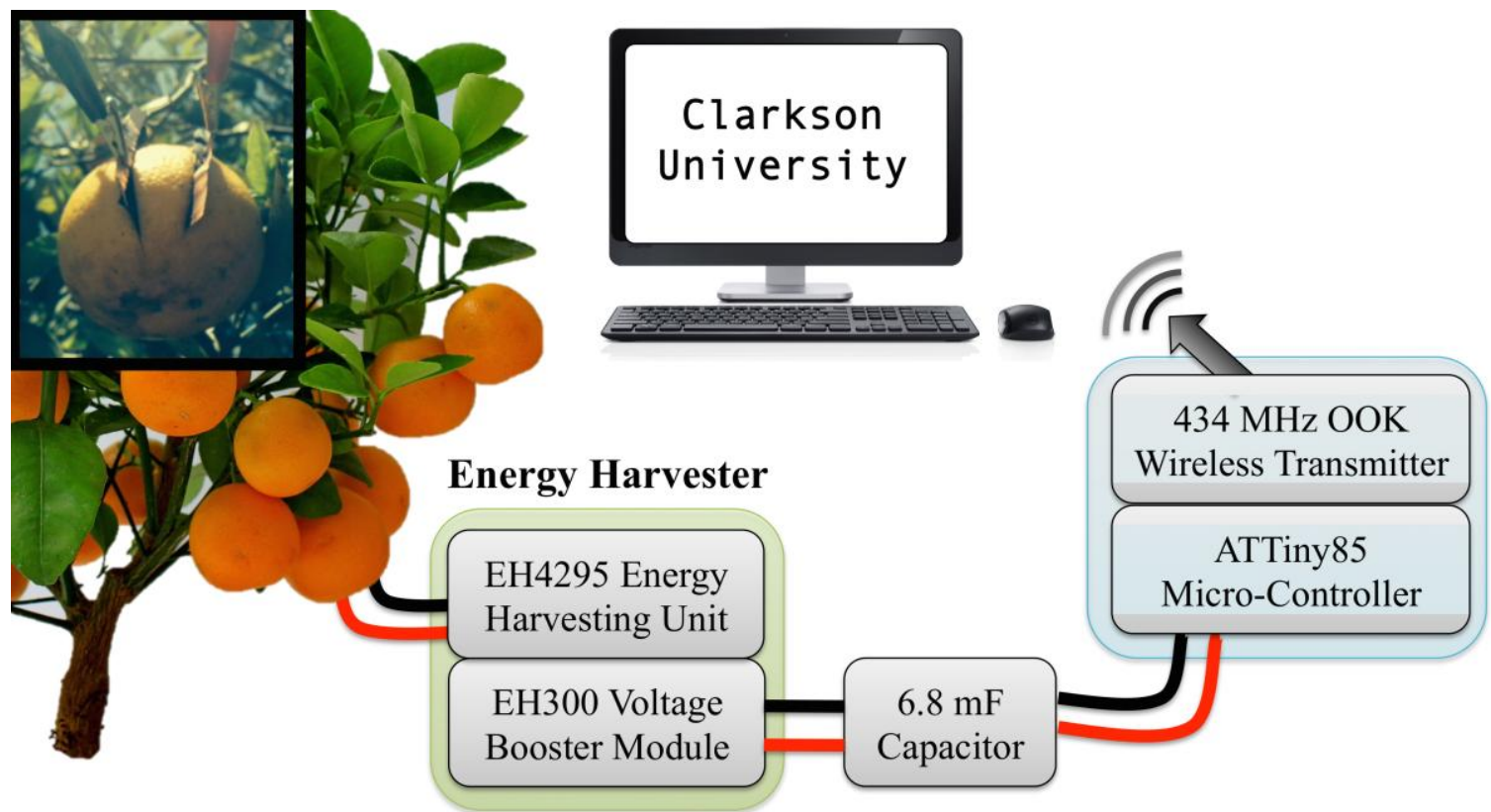

Scheme 1. 

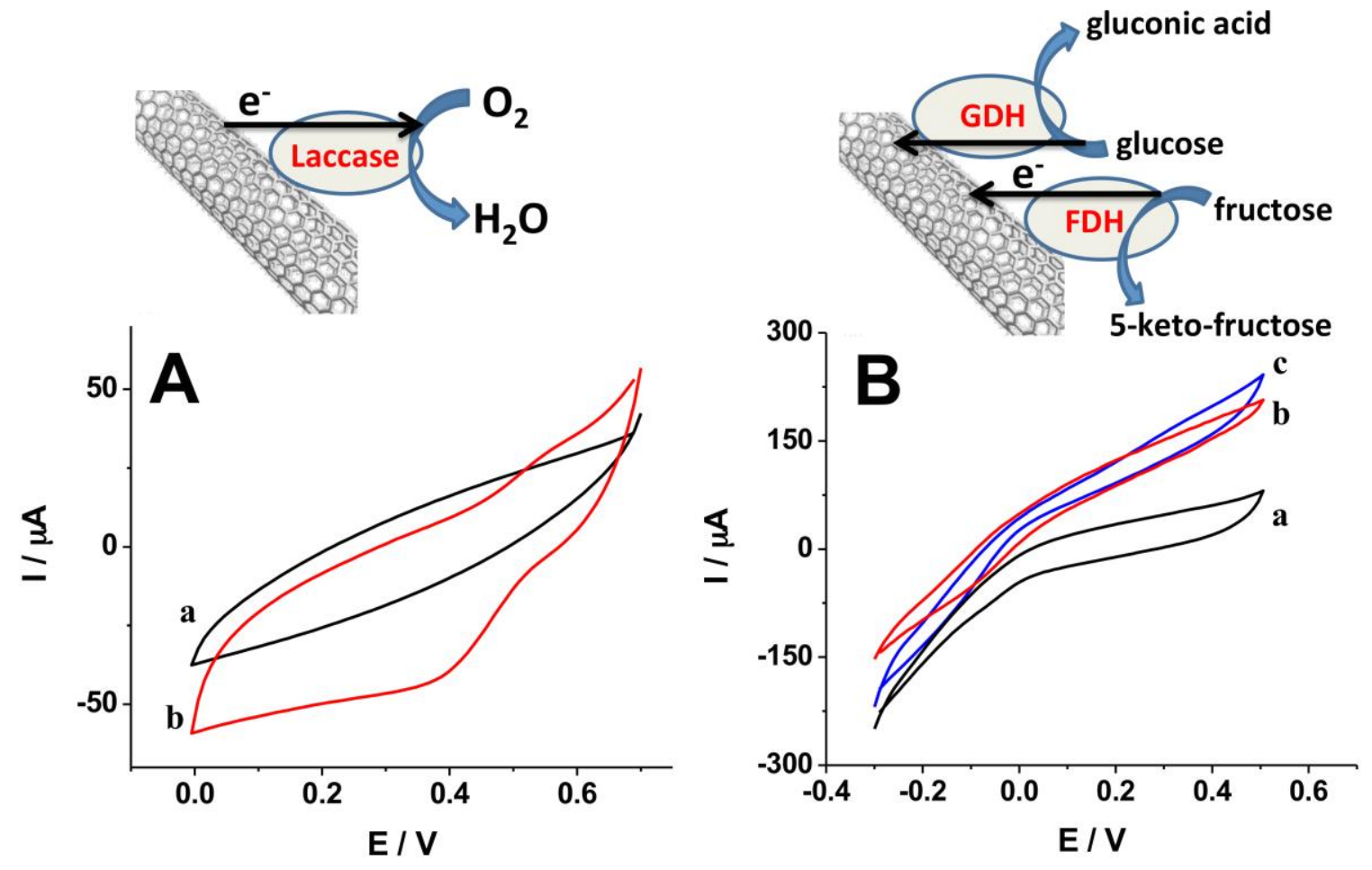

Figure 1. 

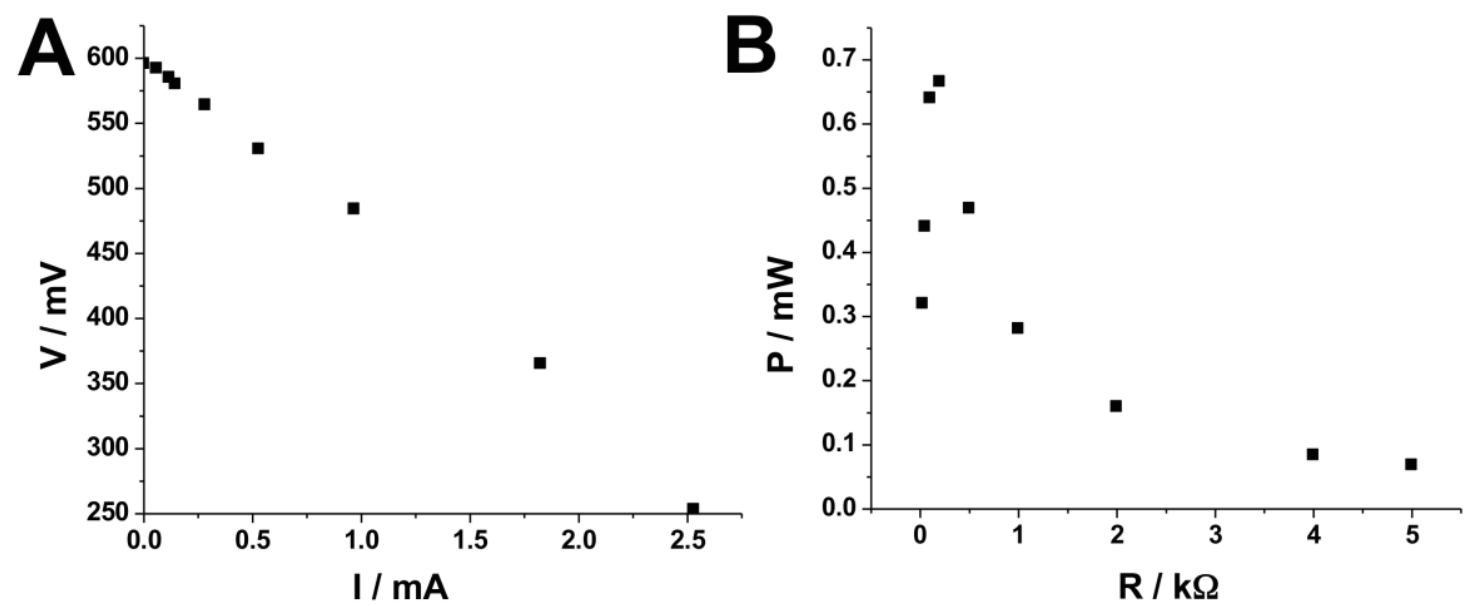

Figure 2. 

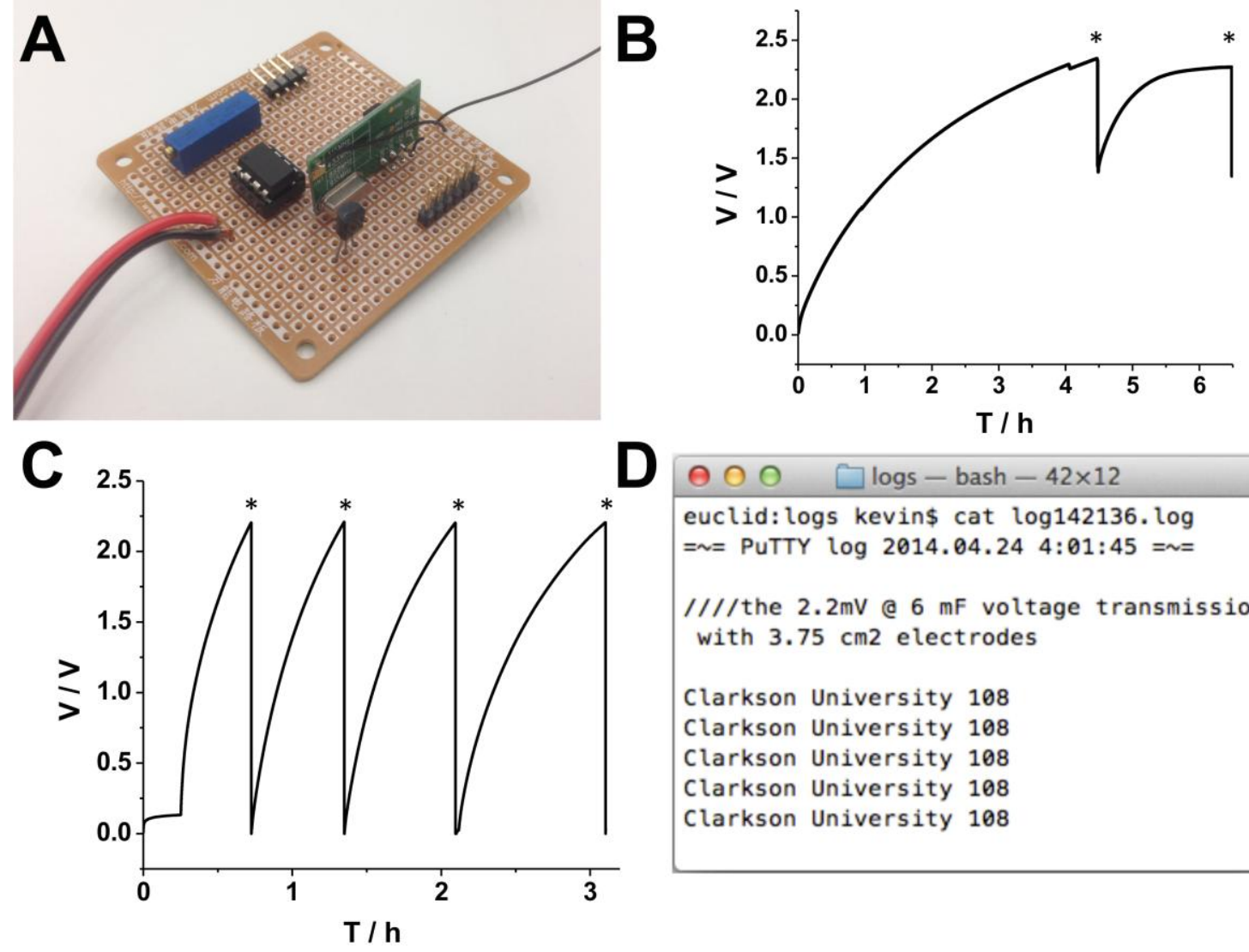

(2) $00 \square$ logs - bash $-42 \times 12$

euclid: logs kevin\$ cat $\log 142136 . \log$ $=\sim=$ PUTTY $\log 2014.04 .24$ 4:01:45 = =

$/ / / /$ the $2.2 \mathrm{mV}$ @ $6 \mathrm{mF}$ voltage transmissions with $3.75 \mathrm{~cm} 2$ electrodes

Clarkson University 108

Clarkson University 108

Clarkson University 108

Clarkson University 108

Clarkson University 108

Figure 3. 


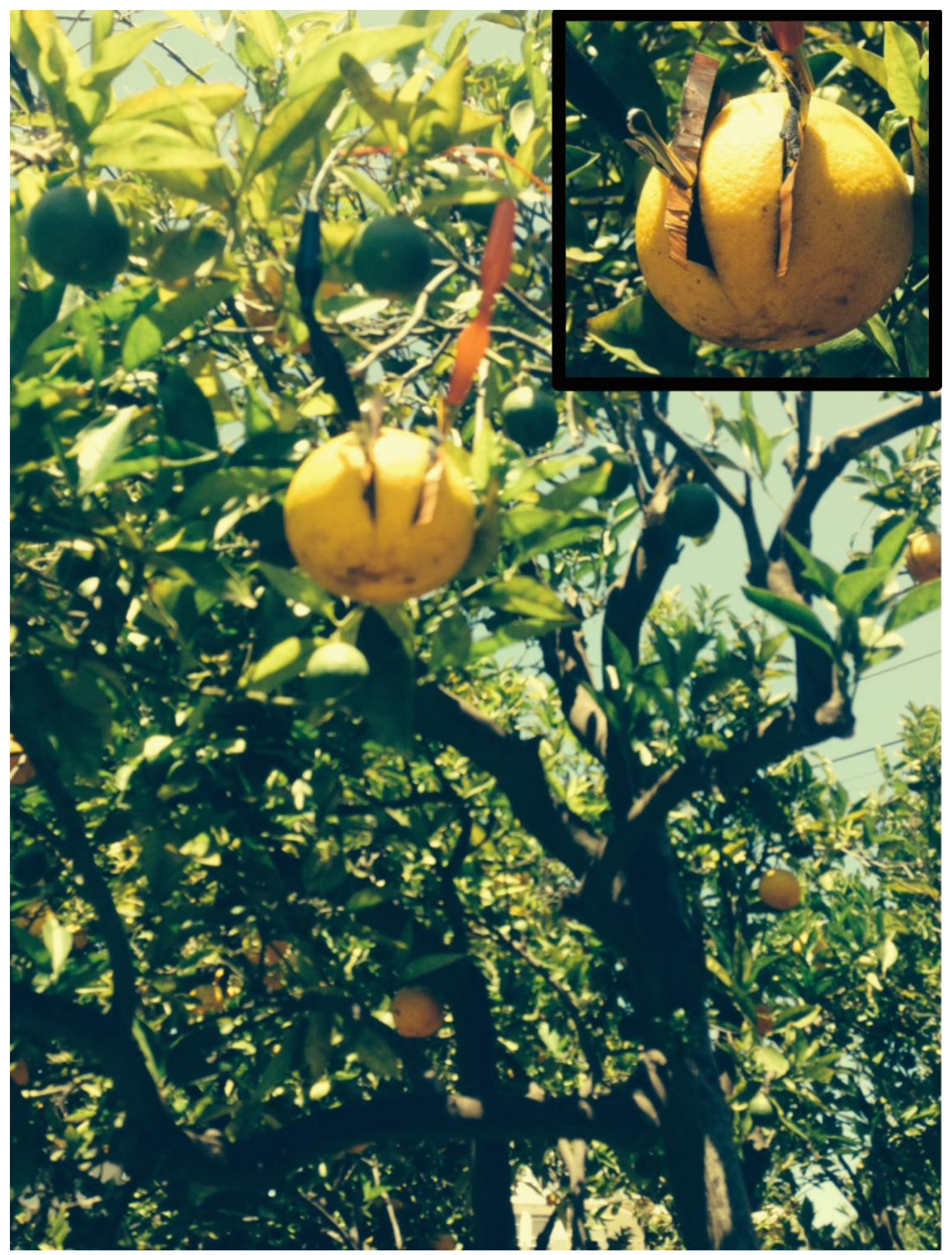

Figure 4. 


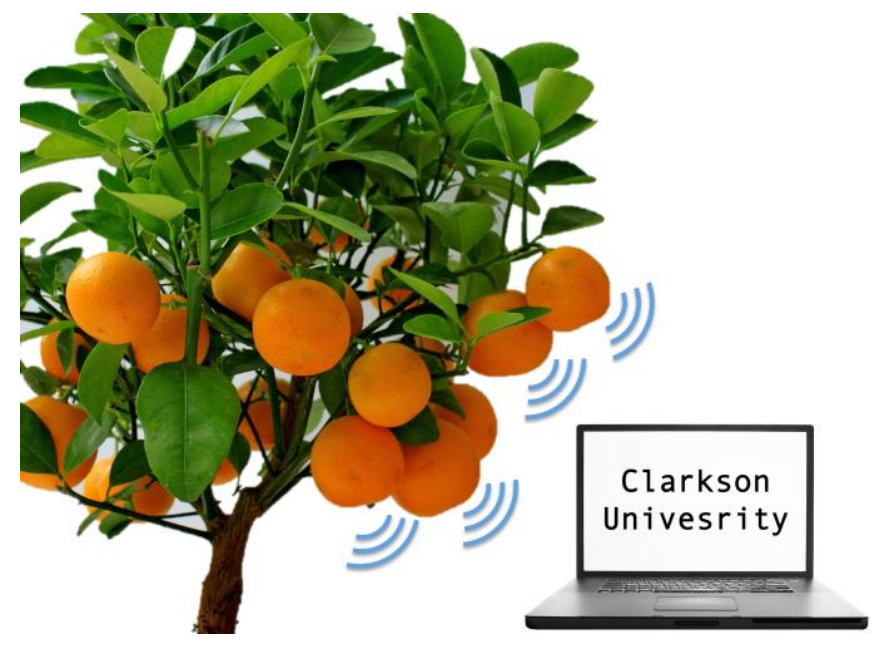

Graphical Abstract 